\title{
Sense of Place and Belonging in Developing Culturally Appropriate Therapeutic Environments: A Review
}

\author{
Bruno Marques ${ }^{1,2, *(\mathbb{D}, \text { Claire Freeman }}{ }^{2}$, Lynette Carter ${ }^{3}$ and Maibritt Pedersen Zari ${ }^{1}$ (i) \\ 1 Wellington School of Architecture, Victoria University of Wellington, Wellington 6012, New Zealand; \\ maibritt.pedersen@vuw.ac.nz \\ 2 School of Geography, University of Otago, Dunedin 9016, New Zealand; cf@geography.otago.ac.nz \\ 3 Te Tumu School of Māori, Pacific Island and Indigenous Studies, University of Otago, Dunedin 9016, \\ New Zealand; lynette.carter@otago.ac.nz \\ * Correspondence: bruno.marques@vuw.ac.nz
}

Received: 16 October 2020; Accepted: 2 November 2020; Published: 3 November 2020

\begin{abstract}
The connection the Māori, the Indigenous people of Aotearoa-New Zealand, have to the land is threatened by the effects of colonisation, urbanisation and other factors. In particular, many Māori suffer significant health and wellbeing inequalities compared to the non-Māori population. In an effort to reduce such inequalities, there is a growing consciousness of the need to better understand the cultural and place-specific determinants that affect the health and wellbeing of population groups in different environments. This article explores how environmental and cultural connections to land enable the development of place-specific and culturally-driven principles that promote the health and wellbeing of Māori populations. It argues that concepts of place, belonging, landscape and wellbeing play an important role in linking environment and culture as well as in contributing to creating therapeutic spatial environments that promote both human health and ecosystems. A set of principles is developed that allows for the landscape design of such therapeutic environments while accommodating the socio-cultural and environmental values that promote health and wellbeing of both Māori and non-Māori people.
\end{abstract}

Keywords: place; belonging; culture; indigenous knowledge; therapeutic environments; landscape architecture

\section{Introduction}

The Māori of Aotearoa-New Zealand contend that the relationship they have with the land shapes how the cultural, spiritual, emotional, physical and social wellbeing of people and communities is expressed. The combination of a dominant culture of New Zealanders of European descent with a highly urbanised society has resulted in the deterioration of the quality of ecosystems and, with it, a loss of Māori cultural values present in and associated with landscape [1]. Despite integration and urbanisation of Māori populations into a Westernised way of living [2], Aotearoa-New Zealand remains a victim of the ironclad powerhouse that is the Western government paradigm. This has led the Māori to suffer cultural and humanitarian injustices at the hands of British colonisation, many of which left lasting effects that still influence Aotearoa-New Zealand's psyche [3-5]. Chief among these stand racial segregation, illegal confiscation of land, cultural disconnect and associated poor health. A lack of understanding in health care contexts [5-10] has led many Māori to avoid mainstream healthcare as they do not feel safe or respected. Consequently, a substantial level of spiritual damage has been reported, contributing to the loss of rangatiratanga (self-determination) and control over Māori taonga 
(possessions and treasures) within a Māori value system [11] and a decline in Māori culture and identity $[5,10,12]$.

While most current ecological, social and health models follow a predominantly Westernised approach, many other cultures, such as Māori culture, embrace a more holistic approach to ecosystems that relates to the health and illness of our natural and built environments. This holistic approach tends to focus on interconnectedness with landscape through the physical, social, environmental, emotional, spiritual, psychological and cultural wellbeing of the individual and community [13-15]. The longstanding connection with the land through forests, wetlands, rivers, coastal areas and mountains provides Māori with a sense of identity, belonging and wellbeing. This is cultivated by all individuals who engage with keeping the human-nature relationship in balance as part of their daily life and wellness [16], experiencing the natural environment as home [17] and forming their knowledge and worldviews. Therefore, sense of place is understood as cosmology and culture passed on orally through generations, which in turn roots Māori and any other Indigenous people to their tribal land spiritually, emotionally and ethically, establishing a sense of belonging simultaneously. The people and the land are one.

Both sense of place and place identity have spawned interest among various disciplines, from social sciences to art and design. As a multi-faceted and layered process that characterises the strong bond established between individuals and important places, sense of place and place identity are crucial components of the discourse around identity, attachment and dependence $[18,19]$. While many Māori tribes have experienced a significant change over time, they maintain a healthy relationship that connects their identity and attachment to specific environments, constructed primarily through whakapapa (ancestral ties) and tribal affiliations as well as stories and myths that convey the significance of that particular place [20,21]. In addition, the benefits of place attachment and identity directly correlate with the physical and psychological wellbeing of any population that retains strong social relationships and active cultural associations with their traditional lands and resources [10,22,23]. Research has shown that Māori suffer significant health inequalities in comparison to the dominant colonising culture [24,25]. Evidence shows that these inequalities can be partially addressed by gaining a deeper understanding of the social and cultural determinants of health, applying Indigenous views of health and developing better definitions of the term wellbeing $[7,10,25,26]$.

This article explores how environmental and cultural (dis)connections to land enable the development of place-specific and culturally-driven frameworks that promote the health and wellbeing of specific populations in a given setting. It argues that concepts of place, belonging, landscape and wellbeing play an essential role in linking environment and culture as well as in contributing to therapeutic environments that promote both human health and ecosystems. It looks at the value of potential frameworks that incorporate the importance of place. The capacity to be emplaced is fundamental to the experience of humanity and of a specific environment. Displacement detracts from and abstracts personal identity; to be displaced is to exist without a sense of who we are. Situatedness is to be orientated towards the spatial, social and temporal characteristics of place, invoking the importance of landscape identity. This can be considered a grounding, 'realising' force that distinguishes place and space. To be placed or situated is integrally a restorative and strengthening process. The first part of this article should be understood as an attempt to draw together and deliberate upon the literature that recognises the qualities of place and the relationships and meanings that are attached to belonging to a place. The second part engages in a discussion that aims at defining principles that can be applied in the design of such places and critically evaluates their responsiveness to 'place' and 'belonging' as design principles. These principles can allow for the design and spatial planning of such environments while accommodating the socio-cultural and environmental values that promote the health and wellbeing of both Māori and non-Māori people. While there is a need for engaging with the existing ecological qualities of our landscapes, designing a landscape or a site entails a deep listening to the qualities of a place as real and lived as opposed to a demarcation of the abstracted spatial parameters of sites. 
A co-evolution is needed that not only takes onboard the ecological predicaments of sites but recognises that sites can accommodate our needs as we live through them.

\section{Materials and Methods}

A comprehensive search was performed using Google Scholar and electronic databases as well as landmark book publications. Search terms such as "belonging", "culture", "environment", "health", "landscape architecture", "landscape identity", "place", "place identity", "place attachment", "Māori", "Mātauranga Māori" (Māori knowledge), "sense of place", "situatedness", "Tikanga Māori" (Māori traditions and customs), "therapeutic environments", "traditional knowledge" and "wellbeing" were used to identify environmental and cultural connections to land and how those promote the health and wellbeing of a specific population in a given setting. Only peer-reviewed publications were chosen for the subsequent selection of articles. One hundred and twenty studies were evaluated based on title and abstract. When the relevance of a paper was difficult to ascertain after reading the abstract, then the full text was read to decide whether to include it or not. Following this first selection, seventy studies remained. A further twenty studies were excluded based on the content of their full text, resulting in fifty studies remaining for this review. The articles were critically evaluated by conducting a strengths and weaknesses analysis of each study and by considering their relevance in promoting health and wellbeing through sense of place and sense of belonging. This critical literature review covered studies that focused on association rather than causation [27] as a way to reveal a number of themes and relationships. These themes and relationships were used to draw together the principles deducible from the range of literature within their function as conducive to forming a 'sense of place' and a 'sense of belonging', and according to associations that were empirically evaluated by published studies.

\section{Sense of Place}

The functions of body and mind have been considered separate in the modernist understanding of the production of experience. The concept of embodiment challenged this dichotomy, recognising that experience, as accessing knowledge, was conducted as a whole, resolving the physical and biological functions, and reframing the body as a site of "lived experience, and a centre of agency, a location for speaking and acting on the world" [28] (p. 10). As the body is the human organism, "the process of embodiment is one and the same as the development of that organism within its environment" [29] (p. 259). Emplacement extends the holism imparted by the paradigm of embodiment to the "sensuous interrelationship between body-mind-environment" [30] (p. 7). Sensory experience is capital to any understanding of emplacement as it "always implicates the intertwined nature of sensual bodily presence and perpetual engagement" [31] (p. 94). How a body produces and receives meaning is subject to its emplacement within the world. Emplacement, then, is a tool for managing the relationships between bodies, minds and the environment, responding to the study of consciousness and objects of direct experience. It accords significance to notions of materiality and (inter)sensoriality. Emplacement operates as a useful paradigm through which to engage the essence of experience of place, equating experiencing with knowing. To evoke the literature that makes sense (and use) of emplacement as a theory of human experience in space, the following pages discuss the literature that invests in sensory engagement within space, the locality of place and literature that broaches the intra-human relation we enter with the environment.

\subsection{Intersensoriality and Cultural Tuning}

Sensory experience is made salient by the 'emergent paradigm of emplacement' just as it justifies the latter. Shimojo [32] verified our understandings of perception as not a 'modular function', but rather cross-modal interactions are the rule and not the exception in perception [32]. While they substantiated their assertions with behavioural analysis and brain imaging, the comparative concept amongst social scientists is neatly summarised as 'intersensoriality'; the notion that the senses do not 
operate individually but as a combined operation to convey information from the world. Perception, our conditional experience of the world, is constituted through the function of and interaction between the senses. Rodaway [33] conceived of senses as a perceptual system which "emphasises the interrelationships between different senses (.. ) in perception and integration of sensory bodily and mental processes" (p. 19). Rodaway [33] extends the idea of interconnected senses by advancing the notion of ecological optics, highlighting "the role of the environment itself in structuring optical (auditory, tactile, etc.) stimulation" (p.20). Information, interpretable through sensorial experience as knowledge, exists within and throughout the environment. Therefore, being within a space consists of consuming its held information through sensorial engagement. In simpler terms, this is understood as experiencing a space. While it contorts our understanding of simple notions, the way in which an experience is conducted and mediated in a space as well as received through a system of interconnected senses is highly valued. Harris [34] continues in the vein of Rodaway, approaching the function of knowledge transmission in relation to a space, writing "knowing is always bound up in one way or other with the world" (p. 1). This assumption, that a person does not need to leave their environment to know it, allows us to think of knowing and experiencing as inseparable from our sensory correlation with the world, within a place.

Howes [30] raises an issue here, arguing that that it is a mistake to produce and adhere to contextless models of perceptual systems. "Without some sense of how the senses are 'culturally attuned' (...) there is no telling what information the environment affords" (p. 144). How we conflate meaning with sensorial stimulation is a culturally-mediated process, shaped by value systems and collectively-held knowledge. Rodaway [33] proposed the notion of 'ecological optics' but it would be misguided to denote the environment's character with a determinist frame over our ability to experience it at the expense of cultural interpretivist frameworks. The density of a bush and the congested acoustics around a waterfall will shape a sensory interpretation of the environment, but Howes [30] argues that the 'cultural tuning' of the senses is more significant in shaping the values we ascribe onto our sensorial experience. This point was recognised by Lefebvre [35] also, who states "space has been shaped and moulded from historical and natural elements, but this has been a political process. Space is political and ideological. It is a product literally filled with ideologies" (p. 31). Foucault and Miskowiec [36] also emphasised this point while challenging the structuralist frame that strictly analysed events according to their temporal axis. "We do not occupy a blank void," they wrote, "we live inside a set of relations that delineates sites which are irreducible to one another and absolutely not superimposable on one another" (p. 23). Foucault's prioritisation of place in demonstrating causal relationships was responsible for a greater interest in place across academic disciplines. These sets of relations encompass prescriptions of space and time that encounter place at a cultural junction.

\subsection{Locality and Thirdspace}

Locality is a valuable approach for determining the situated qualities of a place, and it seems suitable to foreground it with further descriptions of place. Massey [37] treats place as open and active, not as "points or areas on maps, but as integrations of space and time; as spatio-temporal events" (p. 266). Applying Howe's [30] concurrent critique, we might typify place as 'eco-climatic-socio-spatio-temporal events' that cross the dimensions of space and time and incorporate the 'culturally-attuned' social aspect of place. Core to a Māori worldview is the right to be associated with a place: a right to a place for the feet to stand, türangawaewae [38]. Mead describes in great detail the customary format of Māori worldview, interrelating in the production of Māori identity. Tūrangawaewae (place to stand) is intimately connected with whakapapa (kinship system) as they both maintain a personalising force on the individual and collective identity. Türangawaewae as a 'place to stand' is directly conducive with place as a 'socio-spatio-temporal event', for tūrangawaewae, the more complete concept, explicitly accesses location (identifying the spatial), the act of 'standing' (identifying the temporal) and identifies the person who maintains their right to stand in a place in coordination with custom, kinship and parallel claims (the social). With good reason, Mead concludes that "tūranga (stand) is the primary locality" [38]. 
Cresswell [39] proposes his definition of place as, "both the context for practice-we act according to more or less stable schemes of perception-and a product of practice-something that only makes sense as it is lived" (p. 26). Cresswell's definition is easily applicable to Appadurai's [40] conception of locality, as "primarily relational and contextual rather than scalar or spatial. I see it as a complex phenomenological quality, constituted by a series of links between the sense of social immediacy, the technologies of interactivity, and the relativity of contexts" [40] (p. 179). Appadurai [40] applies this phenomenological reading to the analysis of localised subjects, considering a preliminary characterisation of place as the intersection of space and time, itself "socialised and localised through complex and deliberate practices of performance, representation and action" (p. 180). Neighbourhoods, the successful forms of localising practice are at once "ecological, social and cosmological terrains" containing a "context-generative dimension" (p. 183). Appadurai's anthropological approach considers ritual as the means of localisation and the existence of neighbourhoods as prerequisite for the production of local subjects. The theoretical space Appadurai covers in just a few pages is expansive, yet it is clear the limits of his approach are a presumed pre-existence of neighbourhoods and the linear relationship between neighbourhood and locality.

Soja [41] proposes the notion of thirdspace as the trialectic between society, historicity and spatiality, noting the growing socialisation of space in the broadening distinction between the residence and the workplace. This is space that is at once mediated, challenged and charged: "A space that is common to all of us yet never able to be completely seen and understood, an 'unimaginable universe', or as Lefebvre would put it, 'the most general of products'" (p. 56). Similarly, Relph introduces that the unique quality of place is its power to order and to focus human intentions, experiences and actions spatially [42]. This raises the idea that space and place are dialectically structured in human environmental experiences, where space is understood through the places we inhabit and, in turn, places derive meaning from their spatial context. Thirdspace treats place as the interaction amongst 'socio-spatio-temporal events'. The articulation of this trialectic builds upon his materialist interpretation of spatiality, which he saw as "the realisation that social life is materially constituted in its historical geography that spatial structures and relations are the concrete manifestations of social structures and relations evolving over time, whatever the mode of production" [41] (p. 121). In short, Soja explains the origins of the 'terrains' that Appadurai considers essential to the production of locality. Soja considers thirdspace as the causal networks of spatiality, sociality and historicity that are involved in the production of place. The eminence of these localities is drawn from their capacity as lived spaces, embodied as the user is emplaced [43], where the "natural space and the abstract space which confront and surround them are in no way separable" (p. 213). Lefebvre [44] presses a need for an analysis of rhythm to explain the body's lived experience.

\subsection{Flows and Polyrhythmic}

Polyrhythm depicts the sensuous interaction amongst rhythmic qualities of space. Rhythm in this sense is a culmination of the properties of place, time and the expenditure of energy, and their interaction [45]. Not to confuse rhythm with movement, Lefebvre identities repetition, measure and difference as its primary identifiable components. Lefebvre's annunciation is conditional on the experience on the human body, as both contributor and a connective between rhythmic outputs, but he argues they are always "bound to space" [44] (p. 205). In the rhythmic capacity to cross over each other, to 'superimpose', to 'interpenetrate', lies an invitation for other scholars to advance notions of polyrhythm. Benitez-Rojo [46] classifies polyrhythm as rhythms cut through and displaced, "to the point at which the central rhythm is displaced by other rhythms $(\ldots)$ to transcend into a state of flux" (p. 18). Through these definitions, we can infer the rhythmic proportions of place in its continuous reproduction and interactiveness but we are left without a grounded depiction of the qualities of place-specific rhythm. Two following applications of rhythm analysis follow, one representing routine, and one the contested nature of place. 
The transformation of space into place, to charge it with ontological meaning and to incorporate human activity and the investment of energy, requires a conscious moment; an intention or routine [40]. In other analyses, Pink [47] considers the banal fixtures of human routine as culturally-charged and sensuously ordered. Instead of rhythm, Pink [48] refers to 'flows', "experienced as part of the sensory environment of home, but also as things that might be managed or directed in the (re)making of place-making a home "feel right'" (p. 178). Rhythm, then, is recognisable as produced amongst the layers of interaction and engagement with a place and, through endorsement or intervention, calibrates the reproduction of place.

Donnelly [49] facilitates a further consideration of polyrhythmic activity in the creation of place, specifically to postcolonial demarcations of space. The 'mark of colonial relation' permeates through space even as it "can result in polyrhythmic, performatively doubled ensembles" (p. 81). The production of place has been considered with a distinctly colonial character [40], especially in Lefebvre's separate classification of rhythms for the 'dominator-dominated' [44]. Within the unique conditions of contestation and conflict that post-colonialist spaces characterise, wherein meaning and identity interact and cross over each other, the corporeal experience is also a polyrhythmic one [50]. Donnelly asserts the entrenchment of bounded domination within the polyrhythms of the postcolonial and identifies cultural museums as sites where this relationship is purported to be managed but is also made visible [51]. "Heterogenous sites of spatial production" capture the instances where multiple modes of cultural production inhabit the same site, as is often the case in postcolonial contexts [51] (p. 800), suggesting, perhaps, it is not the prescription of/for place that matters but the facilitation of its capacity to be lived and experienced through bodily emplacement.

The intimate connection of culture and place extends beyond the biophysical aspects of land as it also encapsulates the mental and spiritual dimensions of life. This is of particular importance to Indigenous communities as land and places are seen as an extension of a sense of self and collective cultural being [10]. In particular to Māori, reciprocity and interconnection between individuals and wider social affiliations, as well as entities that populate the environment, are core to the experience of place and ultimately enhance the sense of belonging [52]. Each experience becomes site-specific and varies from place to place, reflecting the weaving of whenua (land), türangawaewae (standplace), whanaungatanga (kinship), whānau (family), wairua (spirit), hinengaro (mind, heart), whatumanawa (feelings) and tinana (body). This conceptualisation of sense of place enables a broadening from place as ecological processes to encompass the cultural and spiritual significance and dynamism of specific places as part of experiencing and belonging to a place as well as in contributing to the identity of self (Figure 1). Caring for place and landscape through a socio-cultural and spatial perspective is of high relevance to Māori as it characterises their sense of belonging.

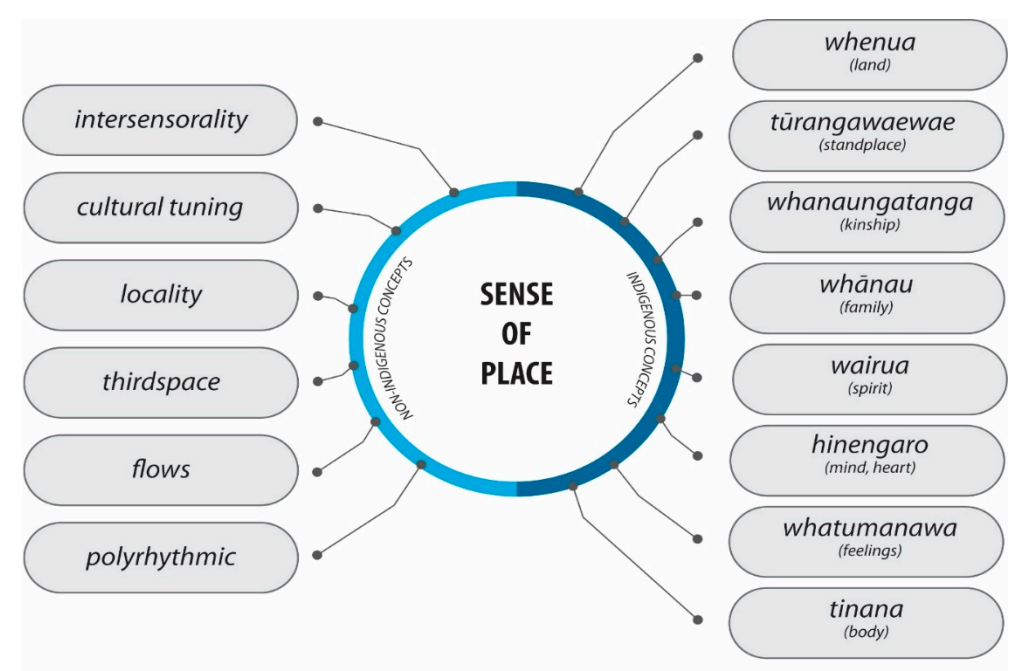

Figure 1. Summary of findings for Sense of Place. 


\section{Sense of Belonging}

In the sense of spatial experience, belonging is a concept that frames how we can view interaction with and habitation of place through social frameworks. The theme of emplacement encompasses the experience of the individual in space, while belonging coordinates the domain of the social, political and cultural in relation to the production of place. Considering the potential of 'belonging' to translate values and ideology into space, it can further inspire the production of frameworks that heed social and environmental principles in the design of place. Responding to the framework of belonging affords the researcher or the spatial designer the capacity to consider place as space shared between cultural and environmental concerns; a natural order fundamental to kaitiakitanga (guardianship). This section engages with the literature that dissects the relationship of belonging to place, according to prevalent cultural perspectives in Aotearoa-New Zealand. Incorporating Māori cultural perspectives brings reason to consider literature on postcolonial space that incites the political and cultural frames of British imperial ideologies that interact, on a very real level, with the social capacities of space and challenge senses of belonging. If we engage with place as space that is situated through the practices of belonging, then it is necessary to consider the values and ideologies that engender this relationship. We must also consider place in coordination with its postcolonial context and engage the literature on how this relationship shapes political issues and cultural memory. As such, this section invokes postcolonial theory, in relation to both postmodern geographies and the particular historical and social context of Aotearoa-New Zealand that shape what belonging means, by approaching concepts deeply imbued in Mātauranga (knowledge) and Tikanga (customs and values) Māori, such as whenua (land), kaitiakitanga (guardianship) and whakapapa (genealogy).

\subsection{Whenua}

Whenua (land or placenta) carries a multiplicity of meanings which, for the purposes of this review, are considered conjunctively. In this sense, Mead's treatment of the definition of whenua as inseparable in a thick description of Māori cultural practice follows:

"The whenua is the medium between the mother and the child, succouring a new life. After birth the whenua, as land, succours the new whannau. The two whenua are similar. Both are real. Whenua as placenta allows a foetus to become a baby, a small human being with all the potential to become a strong and healthy adult. Whenua, as land, sees that person develop and grow, make their contribution to society and then be 'born' into the spirit world". [38] (p. 230)

The dualism in Mead's explanation of whenua is purposeful as it develops the readers' capacity to distinguish the connectedness of the body and the land, not to distinguish between the body and the land. This is not just a conceptual alignment of the human experience with the land but a customary ordering of human relationship within place, for Mead continues to richly describe the ritual of placental burial as incorporating two notions of whenua in physical and semantic alignment [38]. Whenua, the environment in which people live, operates as a "foundation of their view of the world" and the "means of giving reality to the [social] system in the forms of residences, villages, gardens, special resource regions and so on" (p. 208). Mead states that the 'net effect' of "cultural bonding mechanisms and traditional tikanga practices was to develop a relationship with the land" (p. 209).

\subsection{Kaitiakitanga}

Whaanga [53] introduces belonging as kaitiakitanga (guardianship or kinship), the practice of the "intrinsic value of all creation where humans exercise kinship [with the environment], rather than domination [over it]" (p. 95). Whaanga systematises the development of Māori cultural values in relation to and through interaction with the imposition of a dominant Pākehā ideological framework. This approach enables the reader to understand Māori ideologies as situated within a New Zealand dominated by a colonial utilitarian approach to natural resources. The work he cites on Māori ethical responses to commoditised human labour introduces terms such as 'hau' and situates ideology within 
a contemporary social context. For instance, kaitiakitanga (guardianship) encapsulates hau (vitality), along with tapu (sacred) and mana (authority). Whaanga defends that the welfare of the people should be sought through a model of management of natural resources embedded in Indigenous values to enhance cultural capacity. A sense of stewardship, as in caring and responsibility for the wellbeing of the land, is deeply rooted in this concept. As Whaanga situates Māori values within the historical context, the reader is faced with their dialectical opposition to Western treatment of landscape and how these distinctions are mediated through the Waitangi Tribunal. The ethos underpinning the expanded prevalence of the Waitangi Tribunal represents a "contemporary emergence and adaptation of Māori and Pākehā values into unique New Zealand settings" (p. 95). The argument laid out here makes the crucial point that Māori conceptualisations of land use and kaitiakitanga (guardianship) are implanted through a series of mediation screens within their postcolonial context and interpretation.

Whaanga's argument draws from the work of Henare [54], specifically as it relates to the function of Indigenous ideology and the contested meaning of place. Henare dissects notions of Māori economic systems: "A Māori worldview finds kinship with ecological economics, the proposition being that economies exist in the ecology and not the other way around" (p. 9). These economies are significant to the integrity of kaitiakitanga (guardianship) as they underpin the notion of what it means to be within the world. Such a perspective makes explicit the confrontation between modalities of thought in relation to the production and treatment of place. Henare applies the notion of economics, a set of incentive-driven interactions that impose themselves over a landscape (usually considered as a resource; passive and exploitable), but repositions it in this context according to Māori ideology. In other words, belonging is constructed through the landscape and within place, not determined over it, in a sense defying the economic philosophies that demarcate place in ordinance with human interest.

\subsection{Whakapapa}

Whakapapa (genealogy) locates the genealogical bonds that connect the living with their ancestors, including those now located as identities in the landscape, in accordance with Māori kinship philosophy. The practice of reciting one's whakapapa accords an authority to the orator's identity and conveys them as living extension of their kinship-relations to the listener. To the function of placing oneself as an operative of kinship obligation, whakapapa establishes the conditions of kaitiakitanga (guardianship) [53]. Mead [38] summarises the function of whakapapa as providing "identity within a tribal structure and later in life gives an individual the right to say, "I am Māori" ( .. ) In short, whakapapa is belonging" (p. 41). Mead [38] further invokes an understanding authored by the Ministry of Justice:

"The land is a source of identity for Māori. Being direct descendants from Papatūanuku, Māori see themselves as not only 'of the land', but 'as the land'. The living generations act as guardians of the land, like their tipuna [ancestors] had before them. Their uri [descendents] benefit from that guardianship, because the land holds the link to their parents, grandparents and tipuna, and the land is the link to future generations. Hence the land was shared between the dead, the living and the unborn". (p. 216)

Drawing attention back to Appadurai's consideration localising practice, we might consider whakapapa as a way of managing "ecological, social and cosmological terrains" [40] (p. 183). Gatens and Lloyd [55] apply Spinoza's philosophy to the relationship between identity and responsibility, providing the following applicable analysis: "We are responsible for the past not because of what we as individuals have done, but because of what we are" (p. 81). This supports the idea that identity rests beyond our own immediate personhood, a notion at the core of whakapapa's virtue. In conducting an analysis of the formation of identity through shared existence in space, they are useful contributions; however, Rother's [56] ethnographic analysis of the 'shared landscapes' provides a depth and culturally-specific focus that is more fitting to this discussion. She presents evidence that enforces locals' connection, their mana whenua (authority over land or territory), to the place and explicitly discusses the influence that the reverence of a common ancestor, Tairongo, has in developing 
a shared identity that is bound to a place. Amongst the gathered (and shared) experiences representing Rother's fieldwork and her broader analytical interpretation, she manages to represent the meaning of whakapapa as the conjunctive and inseparable function of place and kinship in the production of identity.

\subsection{Indigenous Sovereignty}

The production of place that represents the virtue and authority of these principles-whenua (land), kaitiakitanga (guardianship) and whakapapa (genealogy)—necessitates a general recalibration of the purpose of and commitment to spatial design. A conversion of emplaced Indigenous practices to facilitative and designative frameworks that promote the values expressed in these practices is highly sought; however, this is equally contentious as there is continually the threat of abstracting ideas and displacing epistemologies [57]. Yet drawing from literature that responds to these points may enable us to consider generative design models that are conducive to representing the intent of Indigenous knowledge. The International Indigenous Design Charter, presented at the 2017 World Design Summit in Montreal and endorsed by more than 50 international organisations, results from the collaboration of Indigenous and non-Indigenous designers and identifies core principles by which to coordinate treatment of Indigenous practice in design. Respect for Indigenous knowledge as well as shared benefits and knowledge for those involved in the design process and awareness of the impact of a design are core to the charter, to name a few [58]. Collaboration between Indigenous and non-Indigenous peoples has been structurally enforced by a dialectical view of coloniser/colonised, determining the shape of the relationship as one of 'encounter' [59]. The charter seeks to reorder this relationship. Its purpose is to "facilitate accurate and respectful representation of Indigenous knowledge in all disciplines of design and associated media" [58] (p. 29), bringing attention to the assertion of Indigenous practice within design disciplines and, ultimately, to issues pertaining to sovereignty.

Johnson [60] addresses the landscapes that lie somewhere between the settler and colonised, or thirdspaces of Indigenous sovereignty, and illustrates the point that "evidence of the exercise of Indigenous self-determination can be seen on the landscape of the specific places in which it is exercised" (p. 46). Similar to Soja's consideration of thirdspace [41,43], Johnson aligns his thinking to Bhabha's designation of thirdspace as politicised and towards a socio-spatial phenomenon emanating from "particular discourses and social interactions" [60] p. 7. Where Bhabha [61] considers thirdspace as the site for the "elaborating strategies of selfhood" (p. 1), Butz and Ripmeester [62] engage it as a 'sensibility' that enables the "radically disempowered to discursively reconstruct actual spaces" to the extent of serving their self-determination [62] (p. 8). From these holes in the fabric or generative sites, Māori political activism has historically emerged to contest the erosion of Indigenous sovereignty-from the marae, during the first half of the twentieth century, and additionally in the cities of Auckland and Wellington following the trend of Māori urbanisation at the century's midpoint [63]. Brown [64] does not consider it "surprising that urban Māori looked once again to the whare whakairo (carved meeting house) as an architecture that could represent unity, self-determination and cultural identity" (p. 114). Although it was never lost, it could be argued that extreme marginalisation ignited a principal function in thirdspaces to the sovereign claims of Aotearoa's Indigenous people [51]. To this point, Brown [64] asserts that the wharenui (meeting house) has been "re-contextualised for the contemporary period to meet the aspirations of communities and institutions as well as to confront the challenges of social inequity and physical displacement" precisely due to its "accommodation and embodiment of cultural practices" (p. 115).

A strand of research on cultural sustainability that seeks to prioritise the function of space (as opposed to absorption in its form or symbolic representativeness) praises the foundation of sites conducive to their surrounding ecology and cultural sensitivities. To Brown [64], projects that are rich in material form and conceptually minded may represent environments but are not responsive to kaitiakitanga (guardianship) in a broader, lived sense (p. 108). Kaitiakitanga has, she opines, "manifested itself as sustainable building" (p. 110), signifying a prioritisation of Indigenous cultural 
formats to nurture the environments they sit within. Go-Sam and Keys [65] propose the framework of 'cultural sustainability' to elevate the significance of culturally-informed actors in the attainment of sustainable outcomes in architectural projects. Their argument precipitates a deeper look into the intersection of culture and sustainability, recognising them as distinct modalities in a dynamic relationship. Cultural sustainability works to "resolve divisions arising from taxonomising cultures, by incorporating culture as a parallel and equal dimension of sustainable development" (p. 351). It seeks to distinguish culture as sociologically interactive [66], involved not only in "representing realities but also constructing realities" [67] (p. 214).

Visions of sustainability that are irresponsive to cultural concerns marginalise Indigenous values and entrench postcolonial states of 'spatial repression' [68]. Seeking a postmodern explanation of urban sites as they constrain Indigenous expressions of self, Jacobs [68] makes note of bicultural sites that intend a tone of reconciliation but are attached to performative representations using 'marketable signifiers' of Indigenous value rather than its internalisation through practice (p. 124). In as much as the construction of a place is a coordinated effort of culture and ecology, its situation within spheres of political and cultural interests makes it susceptible to these interests. Reviving Indigenous knowledge as a lens and stimulus for change in the way nature and people intricately interconnect, re-establishing holistic ideologies of harmony and union between the two and employing concepts such as whenua (land), kaitiakitanga (guardianship) and whakapapa (genealogy), a (re)connection is arguably possible. In this vein, Jacobs [68] defends a more politicised interest in thirdspace and the contestation between visions of space in order to assert the presence of Indigeneity in urban settings. Jacobs [68] refers to Indigenous knowledge being treated as a "cultural model for a modernity that might construct itself not around masculinised anthropocentrism, but through a decentred subjectivity" (p. 137). Even as we acknowledge the value of Indigenous practice and philosophy in the Indigenous Design Charter, for example, and 'thirdspace sensibilities' [60] to engage a participatory self-determinism, Jacobs applies a postmodern geography to remind us that spatial developments are already engaged in a socio-spatial context that is as much shaped by historical politics as it is by the intention of the designer. Harnessing the natural environment can facilitate the healing of people's mental, spiritual, physical and social wellbeing as well as deepen their re(connection) to nature, enhancing one's sense of belonging (Figure 2).

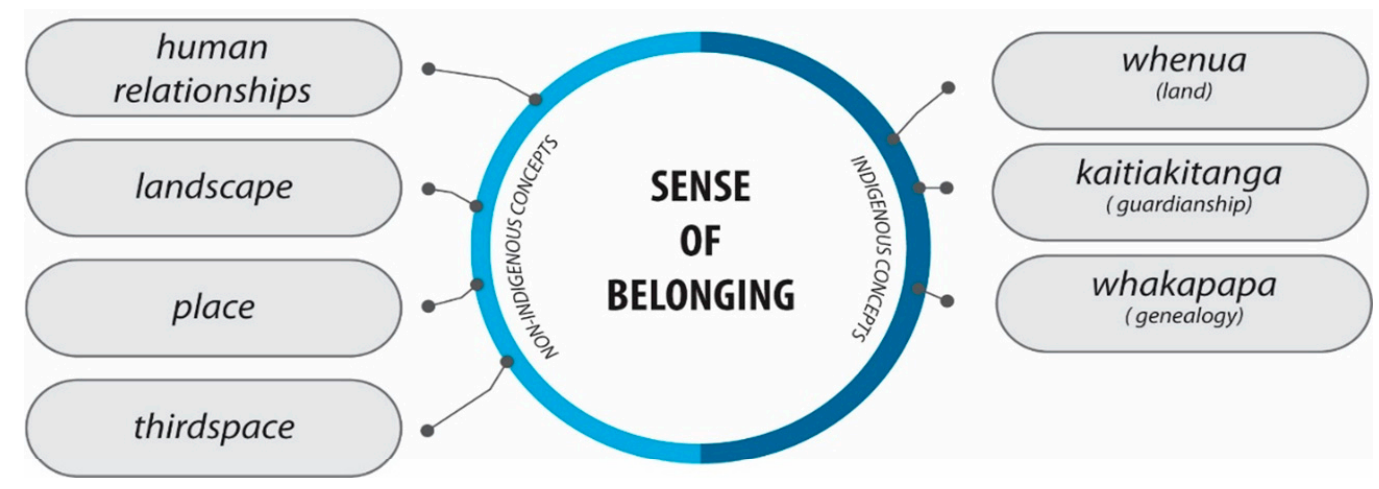

Figure 2. Summary of findings for Sense of Belonging.

\section{Discussion and Principles}

This article has attempted to engage literature to qualify an understanding of place, in how people conduct experience through it and how people distil and impose cultural meaning within it, with particular reference to Māori. Such a discussion strengthens the theoretical toolkit one must adopt in considering the ecological and social specificities of place. As place is formative of the person, so is personhood formative to place; yet how exactly can a site be designed responsively to a dynamic of its own living self, to subsume and be subsumed? 
In this section, we draw together the principles deducible from the range of literature discussed so far within their function as conducive to forming a 'sense of place' and a 'sense of belonging'. We aim to provide clarity to these two abstract notions by recognising certain characteristics or embodiments of these principles spatially. It is proposed that a reconfiguration of their normative functions is necessary for a healthy or valued space in order to provide a set of priorities for engagement in landscape design and other spatial disciplines and to identify priorities for its occupants and provide for its spatial coordination. We will then apply these needs to frame the discussion of a design framework to respond to the specifics of place and cultural interest: making the case for the adoption of a therapeutic environments regenerative design framework.

A sense of place, as the reviewed authors have already suggested, consists of an interrelationship between spatiality, sociality and historicity [43], where it is both the context and product of practice [39]. Mang et al. [69] contribute to the understanding of the spirit of place as "the living ecological relationship between a particular location and the persons who have derived from it and added to it the various aspects of their humanness" (p. 48). The ecologically-minded 'spirit of place' runs parallel to how the aforementioned scholars conceived of place as a socio-spatio-temporal event nearly two decades later. In other words, spirit of place and sense of place become inseparable components as both gather the biophysical and tangible aspects of landscape, through its geologic, hydrologic and climatic attributes, with cultural and intangible values associated with narratives, stories, customs and philosophy of nature. In response to the range of literature addressed and as an attempt to distil it for practical use, the following defined 'sense of place' is suggested by the authors of this paper as one that brings together the tangible and intangible values of landscape: an experiential engagement wherein humans consist as consumers of place, through inter-sensorial [33] and polyrhythmic [45] networks, and as producers, culturally attuned to environmental information [30] and socialising and localising place through deliberate practices [40].

A sense of belonging is contingent on recognising a place to belong to, and therefore, a developed understanding of a sense of place is central to its engagement, even as it maintains its own characteristics. Belonging is deeply enshrined in the politics of identity and especially of the networks of responsibility and obligation towards place that are fostered within it [56,70]. A sense of belonging, as proposed by the authors of this paper, is a conjunctive interchange between the interests and the influences that guide our relationship to place. While itself a task of ideological navigation, a sense of belonging is also its result: it is the formation of identity and of personhood, through participating in the production of place. To belong is a need of those experiencing place, but we can understand a sense of belonging as developed through the need to become part of the place through associative elements of kinship: responsibility to care for and strengthen place and the ability to subsist through place.

The International Indigenous Design Charter [58] promotes one possible framework that would indicate certain protocols by which to coordinate engagement with and the use of Indigenous knowledge as a driver. Accordingly, its use would guide the designer's engagement of Mātauranga Māori as a source of knowledge in its own right and would respect the authority of the independence of this knowledge. To incorporate this framework into a design strategy would force the designer to be 'community specific' to "ensure respect for the diversity of Indigenous culture by acknowledging and following regional cultural understandings" (p. 9). It also maintains the self-determination of Indigenous knowledge but would, where feasible, promote the sharing of this knowledge and its benefits. Through the notion of shared knowledge, the implication in the charter is that by promoting this end point of shared benefits and encouraging a mutual respect and cooperation through the design process, a harmony across epistemologies will be shortly achieved. In an Aotearoa-New Zealand context, this could mean the application of intellectual property rights for Mātauranga Māori [71]. It is, in some ways, a de-ontological effort that minimises the extent of difficulties that exist in cross-cultural interaction. Equally concerning is the absence of ecological health or consideration in this design framework. In heightening Indigenous concerns, it seems to rely on an implication that therein will exist a perspective on proper ecological health that should be accorded respect. In its 
sociological focus, it misses opportunities to suggest actual practices through which to coordinate spatially-responsive design outcomes that would appease both Indigenous and non-Indigenous interests. While this framework seems to satisfy the 'cultural appropriateness' keenly sought across spatial design disciplines as an effort to challenge the cultural hegemony of Eurocentrism, it is limited by lack of a collaborative strategy between Indigenous and non-Indigenous that would underpin the virtue of the listed protocols.

Bridging, a transition discourse, as opposed to the possible use of the charter as a framework, initiates from the point of collaborative strategy to the specific purpose of developing cross-cultural knowledge models. Bridging is a collaborative knowledge model that responds to the emerging realisation that "conventional science based on Western paradigms and systems of knowledge is no longer adequate to deal with complexities of environmental management and that knowledge is contextual has opened the space for considering other systems of knowledge in scientific assessments" [72] (p. 317). While the immediate application of bridging has been to ecological discourses, in a wider sense, it responds to the rise of Indigenous voices and accordingly recognises that to "limit our valorisation of knowledge [of Indigenous people] largely to that which pertains to the natural world" is both problematic, repeating discursive patterns of cultural reduction, and ignores the social and political value of Indigenous knowledge systems for the present [72] (p. 134). Instantiation is an integral part of cultural knowledge that links the ideational level of cultural constructs with the phenomenological level of behaviour [73], yet applications of knowledge (their instantiation) should not be confused with the notion that Indigenous knowledge itself is 'uncodified' as such $[73,74]$. How distinctions are made between Indigenous domain knowledge and knowledge instantiation will also determine the success of a knowledge bridging model.

The use of bridging as a theoretical framework for consigning engagement can encourage the 'opening up' of applicable methodologies to seek productive terms of engagement. Bridging is a format of 'reasoning together', applying, amongst others, the mechanism of 'joint problem solving' situating "Indigenous knowledge holders [to] operate as equals with scientists and technical people" [75] (p. 6). This appears a useful framework through which to engage the stakeholders of a design project, functioning as a 'collaborative strategy' necessitated in the previous framework. In emphasising "relational worldviews or ontologies for which the world is always multiple-a pluriverse" [76] (p. 138), bridging would satisfy an engagement with multiple senses of belonging but is perhaps restricted to a navigation of the cross-cultural 'contact zone'. To the purpose of designing a landscape, bridging is fundamentally incomplete as a framework, offering no definitive direction but rather starting points for discussion; yet it maintains value as a discursive tool one might apply to a more comprehensive framework.

Therapeutic environments' regenerative design addresses the concern for sites as 'places', reconnecting "human aspirations and activities with the evolution of natural systems-essentially co-evolution" [77] (p. 26). A therapeutic environment regenerative design strategy entails a three-step process; first, understanding place necessitates a deep listening, a cultivated ability to see sites as 'energy systems'; second, design for harmony involves an engagement with the existing ecological qualities of a site, maintaining an approach to "build(ing) to place, not formula"; third, co-evolution is a recognition of "progressive harmonisation of dynamic systems" (p. 34), recognising the limitations of human control and the possibilities that emerge when place is treated in a partnership; essentially a recognition that sites can expand our needs as we live through them. In landscape, "design manifests underlying societal worldviews, values and knowledge as landscape use and change"; essentially, how we affect the site is in accordance with our imagining of the site [78] (p. 2). The application of an ecological worldview considers sites as living systems, but in doing so (and aligning with earlier discussions of place), it "inherently calls on design to integrate scientific, social, cultural and metaphysical perspectives, knowledge and intentions in artefacts, institutions and processes that promote the sustainability of landscapes" (p. 3). This approach to attach human concerns to natural systems undermines the conflicting claims to land use by integrating human communities 
and economies back into alignment with life processes. It is possible to misinterpret this approach as seeking an ecologically viable endpoint; this is not the case. It seeks to produce place, of which ecological viability is a result and one of many influences. Seeking to integrate concerns and needs, it makes the novel idea obtainable through a "place by place" approach, "discovering opportunities and solutions that are Indigenous rather than generic [77] (p. 36).

If place and belonging are transposed as design principles, therapeutic environment regenerative design extends their viability and value through its holistic approach and, we would argue, legitimises this relationship through a co-evolutionary approach, making explicit these values through their emplacement. Therapeutic environment regenerative design responds to the issue of place-making and does so recognising the human wellbeing and ecosystem health that overlap in motivation and consequence. The recognition of place that underpins regenerative efforts draws designers towards the study of patterns of organising: geo-physical, biological and human, where the visualisation of their interrelation is made clear according to their value added to place [69]. The partnering with place that therapeutic environments' regenerative design framework demands (where place is recognised as specific, real and imagined) fosters a sense of place. The framework's incorporation of human organising patterns amongst non-human organising patterns contributes to a sense of belonging: it is entrenched in the responsibility one has towards these other patterns when they are so explicitly recognised in the design process, recognising that place is alive, and one is in partnership with it [69]. "The built environment can through its design and production contribute to restoring and enabling this psychological connection" between health and access to nature" [79] (p. 57). Therapeutic environment regenerative design's attention to this need, wrapped up in its engagement with the essence of place, makes it appear an applicable and useful framework to the end of place specificity and cultural responsiveness.

A therapeutic environment regenerative design framework navigates the purpose and meaning of place between human and non-human interests, asserting that they can be harmonious when place is prioritised. To produce place means establishing a strong sense of community and belonging that leads to place attachment and identity. What it does not consider well in its currently-used form is contested inter-human meanings concerning the value of place. This is an issue that the incorporation of bridging as an evaluative and mediative mechanism, alongside the other capacities of therapeutic environments, maintains the potential to resolve. In other words, a therapeutic environment needs to accommodate the existing context and intertwine the wider natural and cultural landscapes. Navigating the relational ontologies of place-making is a fundamental aspect of identifying place-specific, culturally appropriate frameworks, without which we are faced with spaces that ignore different needs. The other danger is a landscape that is presumed to be satisfying for all but in fact fulfils nobody: a site without situation. Therapeutic environment regenerative design accords a discursive space for the mediation of conflicting concerns, but as it fails to develop this notion independently (assuming it has undergone prior consideration), we propose the integration of a cross-cultural knowledge model to the benefit of Māori wellbeing. Bridging could be applied in such a way that it is integrated throughout the process of a regenerative design from the outset, not as an afterthought to manage conflicting cultural priorities. The partnership of therapeutic environments needs to be coordinated with the partnership principle of the Te Tiriti o Waitangi (Treaty of Waitangi) [77]. This organisation of theory would equip the designer with a workable framework with which to design a landscape, one eye towards the production of place, the other towards the production of belonging (Figure 3). 


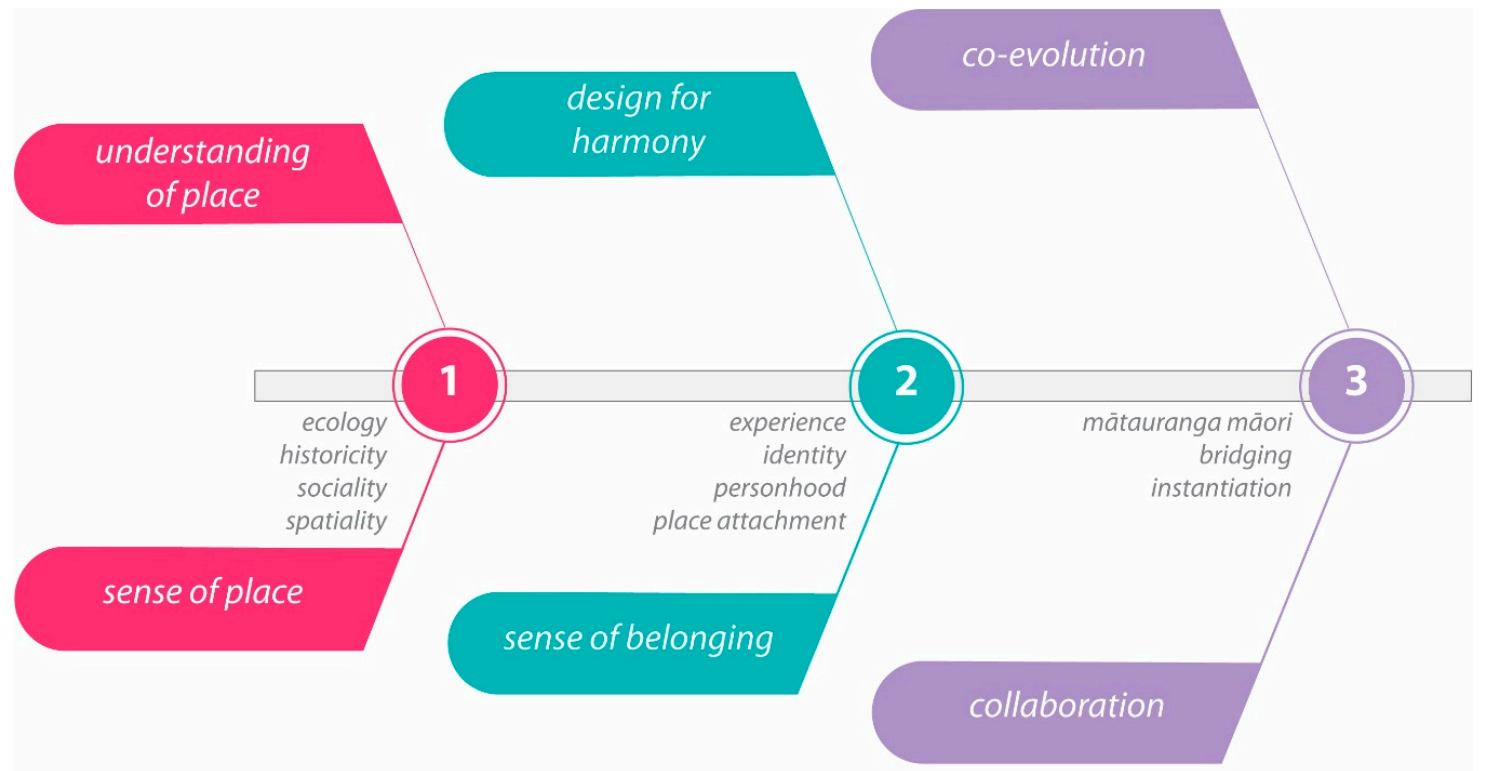

Figure 3. Therapeutic Environment Regenerative Design Framework.

\section{Conclusions}

This paper has attempted to synthesise cultural and sociological knowledge as a method for engaging with the variety of understandings of place and its importance. It has been our intention to provide a range of perspectives and demonstrate that while their emphases or interpretation differ, the role that land as place has in shaping the health and wellbeing of people's everyday lives is immense. While much of the current research on therapeutic environments is deemed useful, it mainly draws from Westernised conceptions of place, belonging, landscape and wellbeing. Existing research tends to overlook the complex matrix of connections that are manifested through the physical, mental, spiritual and socio-cultural relationships to land. For instance, Māori contend that the land provides the context upon which to ground and reiterate the interconnection between culture, identity and health, forming a therapeutic landscape or environment.

Mātauranga and Tikanga Māori offer a broad and deep collaboration of traditional methods, practices and values. For Māori, the principles inherent to therapeutic landscapes are not seen as separate entities. The natural environment and its associated ecologies provide the medium for physical, emotional, mental and spiritual health and wellbeing. Landscape is seen as a whole, generally known as ki uta ki tai (from the mountains to the sea), which brings together people and their environment as well as the importance of inter-generational equity, allowing restoration of the existing landscape and of the entire community. This equally sets the foundation to further research around the conceptualisation of Māori experiences pertaining to wellbeing, sense of place and sense of belonging. Living with nature implies the guardianship of both land and people and places are seen as sacred. By incorporating beliefs of stewardship and kinship with the land, both people and place can better identify in unison, offering new insights into living with nature in urban and rural environments. The therapeutic landscape can enable people to feel a sense of security and belonging with place. These feelings allow for the making of whakapapa with the landscape while healing self and place.

Place-centric approaches enable scholars and designers to connect with landscape and to better appreciate the significance of interconnections that bring forth the lives of local populations, their experience and relationships of the environment and the socio-cultural values attached to those locations. It is the notion that it is the combination of the tangible and intangible properties of a place that directly affects an individual's health and wellbeing. Indigenous place-based approaches enable researchers and designers to explore the contrasting cultures and ecosystems that are interwoven in 
different locations. Creating places where people can deeply connect with landscapes is crucial for the development of health and wellbeing, for both Māori and non-Māori people.

Author Contributions: Conceptualization, B.M.; methodology, B.M., C.F. and L.C.; formal analysis, B.M.; data curation, B.M.; writing-original draft preparation, B.M.; writing-review and editing, C.F., L.C and M.P.Z.; supervision, C.F. and L.C. All authors have read and agreed to the published version of the manuscript.

Funding: This research received no external funding.

Conflicts of Interest: The authors declare no conflict of interest.

\section{References}

1. Durie, M. Understanding health and illness: Research at the interface between science and indigenous knowledge. Int. J. Epidemiol. 2004, 33, 1138-1143. [CrossRef]

2. Meredith, P. Urban Māori-Urbanisation. Available online: https://teara.govt.nz/en/urban-maori/page-1 (accessed on 3 September 2019).

3. Harmsworth, G.R.; Awatere, S. Indigenous Māori knowledge and perspectives of ecosystems. In Ecosystem services in New Zealand — Conditions and Trends; Dymond, J., Ed.; Manaaki Whenua Press: Lincoln, New Zealand, 2013; pp. 274-286. ISBN 978-0-478-34736-4.

4. Marques, B.; McIntosh, J.; Campays, P. Participatory Design for Under-Represented Communities: A collaborative design-led research approach for place-making. In Handbook of Research on Civic Engagement and Social Change in Contemporary Society; Chhabra, S., Ed.; Advances in Human and Social Aspects of Technology; IGI Global: Hershey, PA, USA, 2018; pp. 1-15. ISBN 978-1-5225-4197-4.

5. Reyhner, J.; Singh, N.K. Cultural genocide in Australia, Canada, New Zealand, and the United States. Indig. Policy J. 2010, 21, 1-26.

6. Bryers-Brown, T. "He Reached Across the River and Healed the Generations of Hara”: Structural violence, Historical Trauma, and Healing among Contemporary Whanganui Māori. Master's Thesis, Victoria University of Wellington, Wellington, New Zealand, 2015.

7. Fijal, D.; Beagan, B.L. Indigenous perspectives on health: Integration with a Canadian model of practice. Can. J. Occup. Ther. 2019, 86, 220-231. [CrossRef] [PubMed]

8. Keenan, D. New Zealand Wars-Long-Term Impact. Available online: https://teara.govt.nz/en/new-zealandwars/page-11 (accessed on 29 September 2019).

9. Kingsley, J.; Townsend, M.; Henderson-Wilson, C.; Bolam, B. Developing an Exploratory Framework Linking Australian Aboriginal Peoples' Connection to Country and Concepts of Wellbeing. Int. J. Environ. Res. Public Health 2013, 10, 678-698. [CrossRef] [PubMed]

10. Panelli, R.; Tipa, G. Placing Well-Being: A Maori Case Study of Cultural and Environmental Specificity. EcoHealth 2007, 4, 445-460. [CrossRef]

11. Maaka, R.; Fleras, A. The Politics of Indigeneity: Challenging the State in Canada and Aotearoa New Zealand; University of Otago Press: Dunedin, New Zealand, 2005; ISBN 978-1-877276-53-8.

12. Marques, B.; McIntosh, J.; Hatton, W. Haumanu ipukarea, ki uta ki tai: (Re)connecting to landscape and reviving the sense of belonging for health and wellbeing. Cities Health 2018, 2, 82-90. [CrossRef]

13. Jackson Pulver, L.; Haswell, M.; Ring, I.; Waldon, J.; Clark, W.; Whetung, V.; Graham, C.; Chino, M.; LaValley, J.; Sadana, R. Indigenous Health-Australia, Canada, Aotearoa New Zealand and the United States_Laying Claim to a Future that Embraces Health for Us All; World Health Organization: Geneva, Switzerland, 2010.

14. Mark, G.T.; Lyons, A.C. Maori healers' views on wellbeing: The importance of mind, body, spirit, family and land. Soc. Sci. Med. 2010, 70, 1756-1764. [CrossRef]

15. Stewart, J. Mind-body health connections. In Understanding Health: A Determinants Approach; Keleher, H., MacDougall, C., Eds.; Oxford University Press: Oxford, UK, 2009; pp. 276-282. ISBN 978-0-19-555129-7.

16. Prechtel, M. Secrets of the Talking Jaguar: Unmasking the Mysterious World of the Living Maya; Element: New York, NY, USA, 1999; ISBN 978-1-86204-501-9.

17. Cohn, I. Indigenous Ways-Fruits of Our Ancestors. J. Adventure Educ. Outdoor Learn. 2011, 11, 15-34. [CrossRef]

18. Giuliani, M. Theory of Attachment and Place Attachment. In Psychological Theories for Environmental Issues; Bonnes, M., Lee, T., Eds.; Routledge: Abingdon, UK, 2003; pp. 137-170. ISBN 978-1-351-90790-3. 
19. Scannell, L.; Gifford, R. Defining place attachment: A tripartite organizing framework. J. Environ. Psychol. 2010, 30, 1-10. [CrossRef]

20. Borell, B. Living in the City Ain't So Bad: Cultural Identity for Young Maori in South Auckland. In New Zealand Identities: Departures and Destinations; Liu, J.H., McCreanor, T., McIntosh, T., Eds.; Victoria University Press: Wellington, New Zealand, 2006; pp. 191-206. ISBN 978-1-77656-000-4.

21. Carter, J.; Dyer, P.; Sharma, B. Dis-placed voices: Sense of place and place-identity on the Sunshine Coast. Soc. Cult. Geogr. 2007, 8, 755-773. [CrossRef]

22. Anton, C.E.; Lawrence, C. Home is where the heart is: The effect of place of residence on place attachment and community participation. J. Environ. Psychol. 2014, 40, 451-461. [CrossRef]

23. Tartaglia, S. Different Predictors of Quality of Life in Urban Environment. Soc. Indic. Res. 2013, 113, 1045-1053. [CrossRef]

24. Marriott, L.; Sim, D. Indicators of inequality for Maori and Pacific people. J. N. Z. Stud. 2015, 24-50. [CrossRef]

25. Valeggia, C.R.; Snodgrass, J.J. Health of Indigenous Peoples. Annu. Rev. Anthropol. 2015, 44, 117-135. [CrossRef]

26. Durie, M. An Indigenous model of health promotion. Health Promot. J. Aust. 2004, 15, 181-185. [CrossRef]

27. Groat, L.N.; Wang, D. Architectural Research Methods; Architectural Research Methods; Wiley: Hoboken, NJ, USA, 2013; ISBN 978-1-118-41851-2.

28. Low, S.M. Embodied Space(s): Anthropological Theories of Body, Space, and Culture. Space Cult. 2003, 6, 9-18. [CrossRef]

29. Ingold, T. From Complementarity to Obviation: On Dissolving the Boundaries between Social and Biological Anthropology, Archaeology, and Psychology. In Cycles of Contingency: Developmental Systems and Evolution; Bradford Books; Oyama, S., Griffiths, P.E., Gray, R.D., Eds.; The MIT Press: Cambridge, MA, USA, 2003; pp. 255-279. ISBN 978-0-262-65063-2.

30. Howes, D. Empire of the Senses: The Sensual Culture Reader; Sensory Formations; Berg Publishers: Oxford, UK, 2005; ISBN 978-1-85973-863-4.

31. Feld, S.; Basso, K.H. Senses of Place; School of American Research Advanced Seminar Series; Boydell \& Brewer, Limited: Rochester, NY, USA, 1999; ISBN 978-0-85255-900-0.

32. Shimojo, S. Sensory modalities are not separate modalities: Plasticity and interactions. Curr. Opin. Neurobiol. 2001, 11, 505-509. [CrossRef]

33. Rodaway, P. Sensuous Geographies: Body, Sense and Place; Taylor \& Francis: London, UK, 2002; ISBN 978-1-134-88070-6.

34. Harris, M. Introduction: Ways of knowing. In Ways of Knowing: New Approaches in the Anthropology of Knowledge and Learning; Methodology \& History in Anthropology; Harris, M., Ed.; Berghahn Books: Oxford, UK, 2007; pp. 1-26. ISBN 978-1-78920-415-5.

35. Lefebvre, H. Reflections on the Politics of Space. Antipode 1976, 8, 30-37. [CrossRef]

36. Foucault, M.; Miskowiec, J. Of Other Spaces. Diacritics 1986, 16, 22. [CrossRef]

37. Massey, D. For Space; SAGE Publications: London, UK, 2005; ISBN 978-1-4129-0361-5.

38. Mead, S.M. Tikanga Māori: Living by Māori Values; Huia Publishers: Wellington, New Zealand, 2003; ISBN 978-1-877283-88-8.

39. Creswell, T. Introduction: Theorizing Place. In Mobilizing Place, Placing Mobility: The Politics of Representation in a Globalized World; Place, Sex and Race; Verstraete, G., Cresswell, T., Eds.; Brill Rodopi: Amsterdam, The Netherlands, 2002; pp. 11-32. ISBN 978-90-420-1144-1.

40. Appadurai, A. Modernity Al Large: Cultural Dimensions of Globalization; Public Worlds; University of Minnesota Press: Minneapolis, MN, USA, 1996; ISBN 978-1-4529-0006-3.

41. Soja, E.W. Thirdspace: Journeys to Los Angeles and Other Real-and-Imagined Places; Wiley: London, UK, 1996; ISBN 978-1-55786-675-2.

42. Relph, E. Place and Placelessness; Research in Planning and Design; Pion: London, UK, 2008; ISBN 978-0-85086-176-1.

43. Soja, E.W. Verso Postmodern Geographies: The Reassertion of Space in Critical Social Theory; Haymarket Series; Verso: London, UK, 1989; ISBN 978-0-86091-936-0.

44. Lefebvre, H. The Production of Space; Wiley: Oxford, UK, 1992; ISBN 978-0-631-18177-4.

45. Lefebvre, H. Rhythmanalysis: Space, Time and Everyday Life; Athlone contemporary European Thinkers; Bloomsbury: London, UK, 2004; ISBN 978-0-8264-7299-1. 
46. Benitez-Rojo, A. The Repeating Island: The Caribbean and the Postmodern Perspective; Post-Contemporary Interventions; Duke University Press: London, UK, 1996; ISBN 978-0-8223-8205-8.

47. Pink, S. Situating Everyday Life: Practices and Places; SAGE Publications: London, UK, 2012; ISBN 978-1-4462-5818-7.

48. Pink, S. Doing Sensory Ethnography; SAGE Publications: London, UK, 2015; ISBN 978-1-4739-1702-6.

49. Donnelly, L. Producing Space and Locality Through Cultural Displays: A Creole Case Study. Space Cult. 2017, 20, 81-93. [CrossRef]

50. Rodríguez González, C. The rhythms of the city: The performance of time and space in Suhayl Saadi's Psychoraag. J. Commonw. Lit. 2016, 51, 92-109. [CrossRef]

51. Beswick, K.; Parmar, M.; Sil, E. Towards a Spatial Practice of the Postcolonial City: Introducing the Cultural Producer. Interventions 2015, 17, 789-801. [CrossRef]

52. Pere, R. Te Wheke: A Celebration of Infinite Wisdom; Ao Ako Global Learning NZ: Gisborne, New Zealand, 1997; ISBN 978-0-9597994-9-1.

53. Whaanga, P. Maori Values Can Reinvigorate a New Zealand Philosophy. Master's Thesis, Victoria University of Wellington, Wellington, New Zealand, 2012.

54. Henare, M. A new look at sustainable forestry of the future: Aotearoa-New Zealand philosophy. N. Z. J. For. 2014, 58, 8-12.

55. Gatens, M.; Lloyd, G. Collective Imaginings: Spinoza, Past and Present; Taylor \& Francis: London, UK, 2002; ISBN 978-1-134-70815-4.

56. Rother, T. Shared landscapes: Ownership and Governance of Ōhiwa Harbour (Aotearoa New Zealand). Ph.D. Thesis, Victoria University of Wellington, Wellington, New Zealand, 2016.

57. Morris, G. The Triptych Papers: Lectures in Post-Colonialism, Creolisation and the Epistemologies of Displacement; Choses d' Myrtles: Rio de Janeiro, Brazil, 2011; ISBN 978-1-4679-2331-6.

58. Kennedy, R.; Kelly, M.; Greenaway, J.; Martin, B. The International Indigenous Design Charter: Protocols for sharing Indigenous Knowledge in Professional Design Practice; Deakin University: Geelong, Australia, 2018; p. 36.

59. McHugh, P. Aboriginal Identity and Relations in North America and Australasia. In Living Relationships Kōkiri Ngātahi: The Treaty of Waitangi in the New Millennium; Coates, K., McHugh, P., Eds.; Victoria University Press: Wellington, New Zealand, 1998; pp. 107-188. ISBN 978-0-86473-330-6.

60. Johnson, J.T. Indigeneity's Challenges to the White Settler-State: Creating a Thirdspace for Dynamic Citizenship. Alternatives 2008, 33, 29-52. [CrossRef]

61. Bhabha, H.K. The Location of Culture; Taylor \& Francis: Oxon, UK, 2012; ISBN 978-1-136-75103-5.

62. Butz, D.; Ripmeester, M. Finding Space for Resistant Subcultures. Invis. Cult. Electron. J. Vis. Stud. 1999, 2, 1-23.

63. Larsen, S.C.; Johnson, J.T. Being Together in Place: Indigenous Coexistence in a More Than Human World; University of Minnesota Press: Minneapolis, MN, USA, 2017; ISBN 978-1-4529-5544-5.

64. Brown, D. Contemporary Māori Architecture. In The Handbook of Contemporary Indigenous Architecture; Grant, E., Greenop, K., Refiti, A.L., Glenn, D.J., Eds.; Springer: Singapore, 2018; pp. 107-125. ISBN 978-981-10-6903-1.

65. Go-Sam, C.; Keys, C. Mobilising Indigenous Agency Through Cultural Sustainability in Architecture: Are We There Yet? In The Handbook of Contemporary Indigenous Architecture; Grant, E., Greenop, K., Refiti, A.L., Glenn, D.J., Eds.; Springer: Singapore, 2018; pp. 347-380. ISBN 978-981-10-6903-1.

66. Peterson, N. Other people's lives: Secular assimilation, culture and ungovernability. In Culture Crisis: Anthropology and Politics in Aboriginal Australia; Altman, J., Hinkson, M., Eds.; NewSouth Publishing: Sydney, Australia, 2010; pp. 248-258. ISBN 978-1-74224-009-1.

67. Soini, K.; Birkeland, I. Exploring the scientific discourse on cultural sustainability. Geoforum 2014, 51, 213-223. [CrossRef]

68. Jacobs, J.M. Edge of Empire: Postcolonialism and the City; Taylor \& Francis: London, UK, 2002; ISBN 978-1-134-81085-7.

69. Mang, P.; Haggard, B.; Regenesis. Regenerative Development and Design: A Framework for Evolving Sustainability; Wiley \& Sons Ltd: Hoboken, NJ, USA, 2016; ISBN 978-1-118-97286-1.

70. Massey, D. Geographies of responsibility. Geogr. Ann. Ser. B Hum. Geogr. 2004, 86, 5-18. [CrossRef]

71. Davis, C. Te Matauranga Māori I Te Taha O Te Matauranga. Master's Thesis, Victoria University of Wellington, Wellington, New Zealand, 1997. 
72. Reid, W.; Berkes, F.; Wilbanks, T.; Capistrano, D. Bridging Scales and Knowledge Systems: Concepts and Applications in Ecosystem Assessment; A Contribution to the Millennium Ecosystem Assessment; Island Press: Washington, DC, USA, 2006; ISBN 978-1-59726-038-1.

73. Fischer, M. Culture and Indigenous Knowledge Systems: Emergent Order and the Internal Regulation of Shared Symbolic Systems. Cybern. Syst. 2005, 36, 735-752. [CrossRef]

74. Ellen, R.; Harris, H. Concepts of Indigenous Technical Knowledge in Scientific and Developmental Studies Literature: A Critical Assessment. In Indigenous Environmental Knowledge and Its Transformations: Critical Anthropological Perspectives; Ellen, R., Parkes, P., Bicker, A., Eds.; Studies in Environmental Anthropology; Harwood Academic: Amsterdam, The Netherlands, 2000; pp. 1-34. ISBN 978-90-5702-483-2.

75. Bohensky, E.L.; Maru, Y. Indigenous Knowledge, Science, and Resilience: What Have We Learned from a Decade of International Literature on "Integration"? Ecol. Soc. 2011, 16, art6. [CrossRef]

76. Escobar, A. Sustainability: Design for the pluriverse. Development 2011, 54, 137-140. [CrossRef]

77. Mang, P.; Reed, B. Designing from place: A regenerative framework and methodology. Build. Res. Inf. 2012, 40, 23-38. [CrossRef]

78. Gibbons, L.; Cloutier, S.; Coseo, P.; Barakat, A. Regenerative Development as an Integrative Paradigm and Methodology for Landscape Sustainability. Sustainability 2018, 10, 1910. [CrossRef]

79. Du Plessis, C.; Brandon, P. An ecological worldview as basis for a regenerative sustainability paradigm for the built environment. J. Clean. Prod. 2015, 109, 53-61. [CrossRef]

Publisher's Note: MDPI stays neutral with regard to jurisdictional claims in published maps and institutional affiliations. 